\title{
Public Policy, Innovation and Economic Growth: An Economic and Technological Perspective on Pakistan's Telecom Industry
}

\section{Musleh Ud Din, ${ }^{*}$ Inayat Ullah Mangla, ${ }^{* *}$ Muhammad Jamil ${ }^{* * *}$}

\begin{abstract}
At a time of rapid technological advancements in every field, Pakistan must develop a comprehensive strategy for harnessing science and technology to promote economic growth on a sustained basis. In recent decades, successful economies have moved away from factor accumulation models of economic growth to productivity led growth that is underpinned by technological advancements and innovations. Using the endogenous growth theory as a framework of analysis, the paper will provide a macroeconomic perspective on the importance of technology and innovation for sustainable economic growth. We argue that public policy must be geared to generate robust growth by encouraging investment in research and development (RED) and human capital. The paper will conceptualize the role of technology in the process of economic growth and identify policy areas that can be instrumental in promoting technological modernization and innovations.
\end{abstract}

The paper will also survey some illustrations from Pakistan's telecommunication industry.

Keywords: Policy, innovation, economic growth, technology, telecom, Pakistan.

JEL classification: $\mathrm{O} 14, \mathrm{O} 32$.

1. Introduction

Schumpeter (1942) introduced the idea of 'innovation economics' in Capitalism, Socialism and Democracy, a seminal work contending that evolving

\footnotetext{
* Professor of economics, Pakistan Institute of Development Economics, Islamabad.

** Professor of finance, Haworth College of Business at Western Michigan University; visiting professor of finance, Lahore School of Economics.

${ }^{* * *}$ Independent researcher

We are grateful to Iqra Abbas for her excellent research assistance in conducting and compiling the data and resources used in this paper.
} 
institutions, entrepreneurs and technological change were at the heart of economic growth and not independent forces that were largely unaffected by public policy. Innovation economics is a growing area of economic theory that emphasizes entrepreneurship and innovation. It is based on two fundamental propositions: (i) the central goal of economic or public policy should be to stimulate higher productivity through greater innovation and (ii) markets relying on input resources and price signals alone will not always be as effective in generating higher productivity and thereby economic growth. This is in contrast to the conventional economic doctrine of neoclassical economics.

It is only in the last 15 years that a theory of economic growth focusing on innovation, grounded in Schumpeter's ideas, has emerged. Innovation economics attempts to resolve the fundamental puzzle of total factor productivity growth. The continual growth of output can no longer be explained only in terms of an increase in production inputs as understood in conventional industrialization. Hence, innovation economics focuses on a theory of economic creativity that affects the theory of the firm and organizational decision-making. Innovation economists believe that, in today's knowledge-based economy, economic growth is driven primarily by innovative capacity, spurred by the appropriate knowledge and technological externalities, rather than by capital accumulation as claimed by neoclassical theory.

This theory and narrative of economic growth is known by a range of terms: 'institutional economics', 'new growth economics', 'evolutionary economics', 'neo-Schumpeterian economics' or simply 'innovation economics'. This new economics reformulates the traditional economic growth model such that knowledge, technology, entrepreneurship and innovation are now positioned at the center, rather than being seen as forces that operate independently.

While the US economy has been transformed by the forces of technology, globalization and entrepreneurship, the doctrines guiding economic policymakers have not kept pace and continue to be informed by 20 th century concepts, models and theories. This is in large part because the dominant economic policy models advocated by most policymakers ignore innovation and technology-led growth in favor of macroeconomic tools such as tax cuts for individuals, budget surpluses or social spending, which pale in significance to innovation as a driver of economic growth. 
In this sense, innovation economics is based on the notion that it is only through the actions of workers, companies, entrepreneurs, research institutions and governments that an economy's productive and innovative power can be enhanced, in support of the building blocks of private sector growth and innovation. As a result, when examining how the economy creates wealth, innovation economics looks at a different set of questions such as:

- Are entrepreneurs taking risks to start new ventures?

- Are companies investing in technological breakthroughs and is the government supporting the country's technology base (by funding research and training scientists and engineers)?

- Are regional clusters of firms and supporting institutions fostering innovation?

- Are research institutions transferring knowledge to companies?

- Are trade policies working to ensure a level playing field for domestic companies?

- Are workers becoming more skilled and are companies organizing their production in ways that utilize these skills?

- Are policymakers avoiding barriers or protection for companies against more innovative competitors?

One of the most difficult challenges faced by governments today is to enable and channel this transformation and for individuals and companies to benefit from the self-empowering forces of technological innovation. This will not happen unless they become more open to the idea of 'creative destruction', allowing not only tools and procedures, but also attitudes to be revamped and upgraded. Such tools include well-designed public-private partnerships, especially in terms of modernizing infrastructure. This historical transformation will continue to gain momentum as it expands both in scale and scope. However, its benefits will not be fully realized unless the government takes steps to ensure that positive externalities are internalized and negative impacts are minimized.

Even when a government decides to implement policies that enable economic upgrading and adaption, it cannot do so in isolation. With technology enabling unprecedented mobility and connectivity, countries' jurisdictional power is being eroded. Furthermore, while innovation is important, what is needed even more is a concerted effort on the part of 
markets, institutions and policymakers and the effective use of geographical space.

The empirical evidence worldwide points to a positive link between innovation and economic performance (Fan, 2011). The surge in biotech firms in Germany, for example, is due to research and development (R\&D) subsidies for joint projects. Additionally, innovation capacity explains much of the GDP growth in India and China during 1981-2004, but especially in the 1990s. By linking the sciences sector with the business sector, establishing incentives for innovative activities and balancing the import of technology and indigenous $R \& D$, both countries have experienced rapid economic growth in recent decades.

At a time when rapid technological advancements are occurring in every field, Pakistan must develop a comprehensive strategy for harnessing science and technology (S\&T) to promote sustainable economic growth. To this end, we provide a synthesis of the literature on how developed as well as developing economies have enabled the role of entrepreneurship in a capitalist society. We argue that public policy must be geared toward generating robust growth by encouraging investment in R\&D and human capital. The discussion on policy focuses on entrepreneurship, competition and specific incentives for promoting technological modernization and innovations.

Section 2 provides a brief review of the literature on the determinants of economic growth, emphasizing the role of technology in sustaining longterm growth. Section 3 develops a conceptual framework for understanding the role of public policy in technological advancement and innovation. Section 4 describes the state of technology and innovation in Pakistan's industry sector in general and the telecom sector in particular to identify critical gaps in these areas. Section 5 spells out policies that would encourage technological modernization and innovation in the industry sector in general and the telecom sector in particular. Section 6 describes the state of the telecom industry in Pakistan, focusing on deregulation, the policy framework, market competition and technological modernization. Section 7 summarizes the discussion and underscores key policy implications.

\section{Literature Review}

A vast body of literature explores the determinants of economic growth, emphasizing a wide range of economic and institutional factors that underpin the process of growth. The earliest work on this was the Harrod- 
Domar growth model, which underlined the role of factor accumulation in the growth process. This was followed by the influential works of Solow (1956) and Swan (1956), which stressed the role of technological progress besides factor accumulation as the main drivers of economic growth. These models, however, treated technological progress as exogenous and thus failed to explain how technological progress is shaped by economic and institutional factors, including public policy.

The question of how technological progress influences the growth process spawned a burgeoning literature under the rubric of endogenous growth theory pioneered by Romer (1986) and extended by others (see Lucas, 1988; Grossman \& Helpman, 1990; Romer, 1994). This strand of the literature considers technical progress to be an endogenous process that depends on several factors, including human capital, entrepreneurship and institutions.

Economists have extensively debated the causes of wide variations in growth between different countries, arguing that disparities between growth rates are only in part explainable by different rates of increase in the use of primary factors of production: capital and labor (Easterly \& Levine, 2001). In particular, studies emphasize that growth differences are also attributable to different rates of technological progress on the back of crosscountry differences in returns to scale, the learning-by-doing effects of human capital and the dynamic spillover effects of export-oriented industries (Grossman \& Helpman, 1990, 1994). Barro (1990) underscores the role of public spending in economic growth, emphasizing that the institutional differences implicit in public spending policies significantly explain cross-country differences in growth performance.

The more recent literature argues that factor accumulation and productivity improvements through technological change are themselves endogenous and influenced by deeper determinants of economic growth. By and large, the consensus is that the quality of political and economic institutions - the software of society - matters for economic growth (Acemoglu, Johnson \& Robinson, 2005; Dollar \& Kraay, 2003). The institutional framework shapes the incentives for investment, innovation, trade openness, accumulation of human capital and productivity improvements, all of which contribute to long-term growth potential (Romer, 1994; Grossman \& Helpman, 1994). The role of public policy is also important in that policies can ensure better incentives for entrepreneurship, innovation and the development of new products and processes that are essential to fuel the growth momentum (King \& Rebelo, 1990). 
Some studies highlight weaknesses in institutional structures that prevent effective action to promote entrepreneurship and innovation. For example, despite the tremendous advancement in technology in the West, "Western political and economic structures are, in some ways, designed to resist deep and rapid change" (El-Erian, 2015). When major structural and secular challenges arise, their institutional structures can be a major obstacle to effective action. However, the system works well when economies are operating in cyclical mode.

Finally, some interesting empirical evidence is worth mentioning. Acs (2006) presents robust evidence that entrepreneurial activities vary across stages of economic development. Entrepreneurial activity has a positive effect on economic growth in highly developed countries, but a negative effect in developing nations. A related issue is how public policy varies with stages of economic development. In particular, since entrepreneurship in developing countries is likely to be low, it is useful to formulate enterprise development policies with a long-term focus. For developed countries, both labor market and financial market reforms are needed.

\section{Technology, Productivity and Growth: Conceptualizing the Role of Public Policy}

Economic growth depends on the level of investment, the quantity and quality of human capital and improvements in technology. The fundamental relationship between value-added in an economic activity and its productive factors is expressed as:

$$
\begin{aligned}
& Y_{t}=A^{g_{t}} \cdot F\left(e^{\alpha_{t}} K_{t}, e^{\beta_{t}} L_{t}\right) \\
& K_{t}=(\delta+\sigma) K_{t-1}+I_{t}
\end{aligned}
$$

where $Y$ is the value-added in an economic activity, $g$ is disembodied technical change, $\alpha$ is the embodied technical change in capital, $\beta$ is the embodied technical change in labor, $K$ is capital stock, $L$ is labor, $\delta$ is the rate of depreciation, $\sigma$ is obsolescence, $I$ is investment and $t$ denotes time.

The productive factors in any economic activity depend on factor endowments and the incentive structure, which in turn is shaped by public policies. If the incentives are neutral, the country will specialize in accordance with its static comparative advantage. However, if there are differences in the static and comparative advantages (because certain 
industries may not be mature enough to compete at present, but may have the potential to develop at a later stage), neutral incentives will not be an optimal policy.

For example, in the case of an infant industry such as component manufacturing, a country may not have a static comparative advantage, but a dynamic comparative advantage instead and the government may have to protect or subsidize the industry. Similarly, if the country embarks on a program of imparting specific skills to acquire a certain competitive advantage in the long run, the government may have to intervene and change the incentive structure in favor of such an activity. Accordingly, the need to coordinate industrial S\&T and R\&D policies cannot be overemphasized.

Disembodied technical change $(g)$ arises from better management practices, learning by doing and the overall business climate. A business climate that is conducive to business development, productivity and growth is characterized by an atmosphere in which workers are motivated to contribute to the growth of the firm, better management practices and government facilitation through efficient regulatory policies.

Embodied technological improvements in physical capital (a) help the growth process in a number of ways: by improving the productivity of existing capital, through better selection and adaptation of machinery and equipment in accordance with the country's factor endowments and by stimulating private investment by improving private returns. Similarly, human capital development through higher education, upgraded skills and provision of social amenities $(\beta)$ is instrumental in boosting economic growth. The government plays a pivotal role in improving education standards and initiating skills development programs to boost workers' productivity.

\section{The State of Technology and Innovation in Pakistan}

The state of technology and innovation is far less satisfactory in Pakistan compared with other emerging economies (Figure 1), not least because of poor incentives for technological upgrading and innovation, the weak link between industry and academia (research institutions) and the lack of resources for scientific research and technology development. A serious constraint to achieving global competitiveness is the low productivity of Pakistan's industrial sector (Mangla \& Din, 2015), which is a result of myriad factors, including trade and industrial policies that provide 
little incentive for productivity improvements, weak human capital and the lack of a supportive business environment.

Figure 1: Global innovation ranking scores for selected countries, 2013

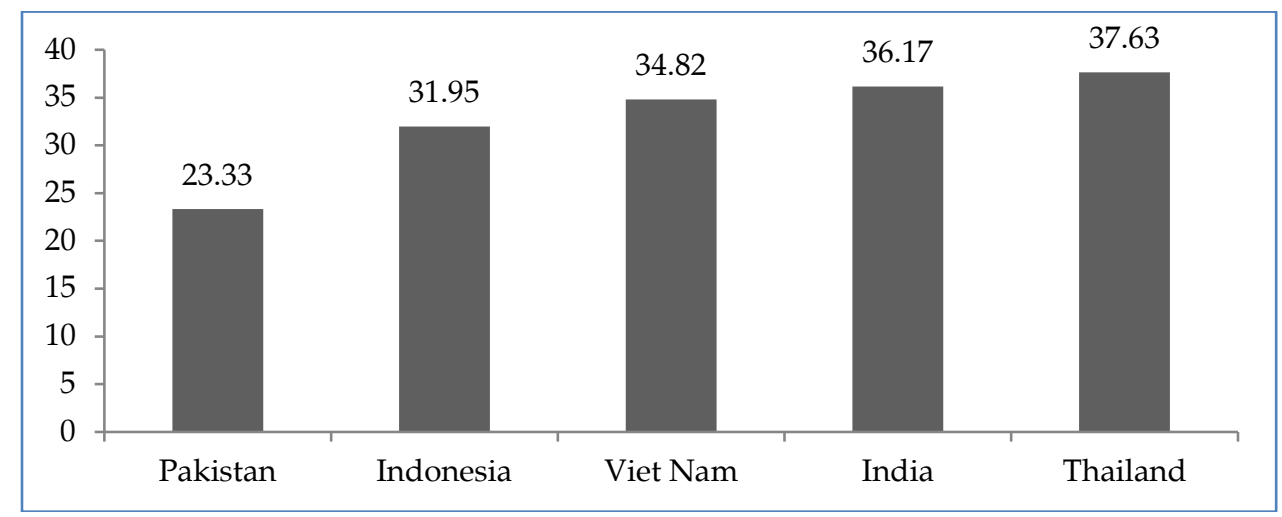

Source: Global Innovation Index.

Pakistan is deficient in skilled human resources that are vital to technological advancement. The retention of technically skilled labor is a serious problem, especially in the information technology (IT) sector where technological changes are rapid and "brain drain" widespread (Hassan, 2014). Pakistan's track record in the development of human resources is not very impressive and its efforts to improve education and skills have not contributed to any significant improvement, not least because of the poor management of public projects in these areas.

A lack of skilled workers not only adversely affects the productivity of existing industries, but also hampers the establishment of new high-tech industries. Pakistan has an acute shortage of electronics graduate engineers and technicians, especially in emerging technologies. There are only a handful of qualified professionals in the emerging areas of digital signal processing, optics, digital communications, microelectronics and microwaves. To make the situation worse, the production of graduate engineers and technicians is not demand-driven, with the result that most employers find that fresh recruits take a long time to become productive (Rahman et al., 2005).

Most Pakistani firms operate at the lower end of technology and lack the capability to adopt high-tech manufacturing processes (Rahman et al., 2005). There has been little R\&D activity in the private sector and public 
sector institutions have not been able to deliver either, resulting in low $R \& D$ capacity (Figure 2).

Figure 2: Global scores in R\&D and high-tech exports, 2013

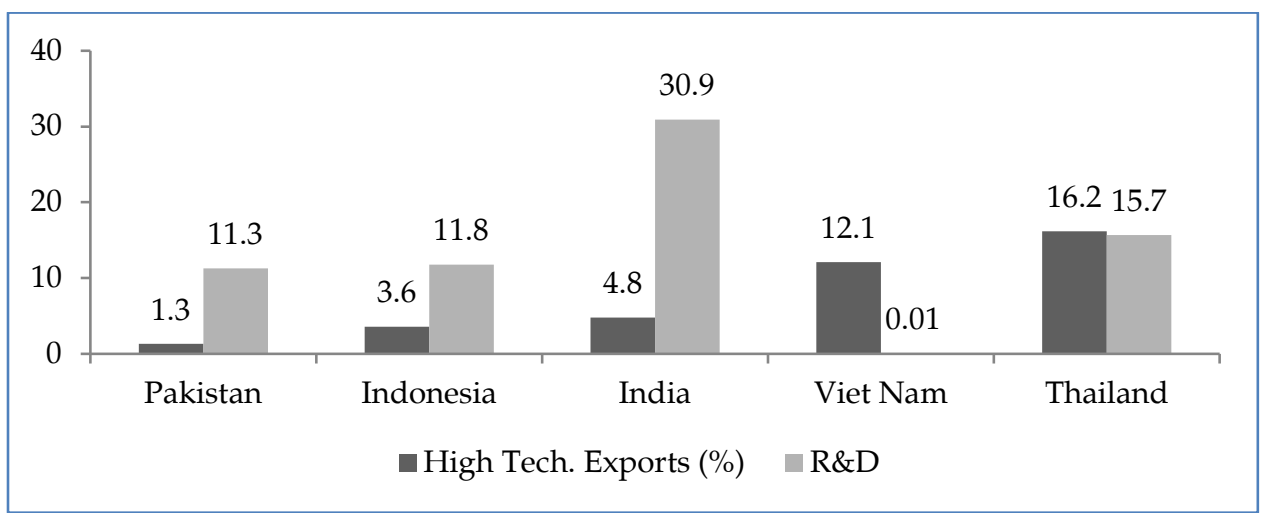

Source: Global Innovation Ranking.

In this scenario, firms need an enabling environment to build their technological capabilities. This has three elements. The first is production capability: the operation and maintenance of existing production facilities to enable efficient operation within the parameters of the technology already employed and to adapt and improve existing technologies. The second is investment capability: expanding capacity and establishing new high-tech production facilities. The third is the capability to innovate and improve the existing technology beyond the original design parameters. While all three need to be promoted through appropriate trade and industrial policies, Pakistan should focus on the first two elements in the short to medium term. Improving its R\&D capacity for developing new technology should be a long-term goal for sustainable growth.

The electronics and telecom industries are among the world's fastest growing industries. Electronics is a key enabler of growth and innovation, underpinning many important industries, including automotive as well as information and communication technology (ICT), consumer appliances, defense, biomedical appliances and other scientific equipment and devices. Despite its large growth potential, Pakistan lags behind significantly in the development of its electronics and telecom industry (Rahman et al., 2005). It is, therefore, imperative that a coherent strategy is put in place to develop these sectors with a view to increasing the country's growth potential and achieving self-sufficiency by reducing its dependence on foreign sources of electronics and telecom equipment and components. 


\section{Public Policies to Foster Entrepreneurship, Technology and Innovation}

It is widely recognized that public policies play a critical role in fostering entrepreneurship and creating an enabling environment for technology and innovation, which are vital to long-run industrial success. ${ }^{1}$ To prepare the country for emerging challenges, the development of S\&T and its interface with industry must be brought to the forefront of industrial strategy. More specifically, there is need to put in place a multi-faceted strategy that is designed to strengthen the key ingredients of industrial success, based on the modernization of technology and innovation. Such a strategy should encompass policies that promote an entrepreneurial culture, improve the quality of human resources, develop R\&D capacity, strengthen market competition and offer incentives to innovate and modernize.

At the outset, it is important to recognize that telecom is a highly innovative field in which new developments take place rapidly. In today's globally competitive environment, telecom firms are under relentless pressure to provide innovative products more quickly, more cheaply and of improved quality. The industry is driven by the demand for products that are smaller, lighter, cheaper and better than what they replace. In this scenario, countries such as Pakistan, which have yet to make their mark in the field of telecom, have a long way to go before an industry that is capable of attaining international competitiveness can be developed.

Pakistan must put in place a development strategy for the telecom sector with the following objectives: to (i) build on the existing capabilities in electronics and telecom, (ii) attract foreign direct investment (FDI) to facilitate the transfer of technology, (iii) strengthen capability in assembling and testing electronic components, (iv) develop and enhance the industry's value-added by moving into activities such as R\&D and (v) support the development of indigenous supply chains.

In order to achieve the broader aim of developing and sustaining a telecom industry with the potential to emerge as a key driver of economic growth, public policies must aim to promote private sector development while emphasizing the role of the public sector as a facilitator. To begin with, an entrepreneurial culture is key to technology adoption and innovation (Acs \& Audretsch, 1989; Audretsch, Keilbach \& Lehmann, 2006). It is entrepreneurs who take risks, start new businesses, develop new ideas and

\footnotetext{
${ }^{1}$ See, for example, Acs and Szerb (2007) and the references cited therein.
} 
products and invest in new technologies (Romer, 1994; Grossman \& Helpman, 1994). Public policies to promote entrepreneurship must be geared toward creating an environment that allows entrepreneurs to take risks and unleash their creative potential.

A business-friendly regulatory and legal environment is fundamental to promoting entrepreneurship. In particular, regulatory barriers to market entry must be minimized to foster the establishment of new businesses that are most likely to lead new technology adoption and innovation. Equally important is to establish institutional mechanisms to ease firm exit, including bankruptcy laws to help businesses close down their operations. As emphasized by Acs and Szerb (2007), such policies are essential to transform an economy from conventional managerial capitalism to a more dynamic entrepreneurial capitalism powered by knowledge, technology and innovation.

Human resource development through better education and improvements in skills is a key determinant of technology adoption, innovation and productivity enhancement. In order to make the transition to a knowledge-based economy, Pakistan must prioritize human resource development. The problems of low productivity and poor product quality can only be addressed by improving the quality of human resources.

Telecommunication is a knowledge-intensive industry that requires substantial investment in human resource development. This entails supporting educational institutions through special grants to initiate and strengthen academic programs in advanced electronics (microelectronics, optics, digital signal processing and digital communications). In addition, educational institutions must emphasize entrepreneurship, commercialization and marketing studies in disciplines that lead to electronics and telecom-related careers. Moreover, the private sector should be encouraged through fiscal incentives to invest in on-the-job training to upgrade labor skills.

It is widely recognized that a competitive business environment that rewards entrepreneurship, efficiency and innovation is essential for sustained economic growth. Such an environment generates the pressure and opportunities needed for innovation and stimulates investment in technology development. It is characterized by market-driven incentives and a level playing field for investors and is supported by a transparent, predictable and consistent regulatory framework and liberal trade regime. 
Besides domestic competition, external competition in the form of openness to international trade can lead to productivity gains through the international diffusion and adoption of new technologies. There is, therefore, a need to maintain competition policies both with regard to domestic commerce and openness to international trade to foster a dynamic entrepreneurial culture as the backbone of a knowledge-based economy.

The government must help deepen the country's technological base by encouraging $R \& D$ at the firm level through $R \& D$ incentives. This means allocating more funds to S\&T research, which underpins an innovative culture. Attaining competitiveness requires $R \& D$ activities focused on improving the operation and maintenance of production facilities, product quality and design and process technologies. This needs a two-pronged strategy to promote R\&D. First, public sector institutions need to be strengthened to provide market-driven R\&D support to firms. Second, the private sector needs incentive to invest in $R \& D$, which can include tax exemptions on expenditure incurred on $R \& D$ activities as well as matching grants for specific R\&D projects.

More specifically, the expenditure incurred in training employees, product development and testing and imports of R\&D equipment and supplies could be made tax deductible. In addition, well-targeted subsidies on the cost of acquiring new technology and commercializing locally developed technology would help firms achieve an efficient scale. This, in turn, would internalize the benefits of improved R\&D capability.

Besides incentives for building R\&D capacity, efforts are needed to propel the industry onto a higher technological plane to produce valueadded goods that are competitively priced in international markets. The government could use fiscal incentives to promote the modernization of technology and innovation at the firm level. These incentives can be classified as those that (i) leave pre-tax profitability unchanged, but result in relatively higher post-tax profitability and (ii) reduce the cost of production and consequently raise pre-tax profitability. Whereas the former includes tax holidays, tax credits and accelerated depreciation allowances, the latter includes all other incentives such as concessions in the import duty on raw materials and capital goods and in the sales tax on output.

The distinction between the two types of incentives is important. The former is effective only if the activity is profitable in the first place, but posttax profits are not high enough to attract investment, while the latter could conceivably attract investment in otherwise loss-making activities as well. 
Specific fiscal incentives to enable firms to upgrade their technology may include duty-free imports of new machinery and equipment. In addition, keeping in view that not all manufacturers have the necessary resources to invest in brand new machinery and equipment, imports of second-hand machinery could be allowed. Since lack of funds for investment in new technology is seen as a major constraint to upgrading technology, a fund for this purpose needs to be created to provide long-term financial support for installing modern machinery and equipment.

Encouraging FDI can be instrumental in attracting high-tech manufacturing enterprises to locate their facilities in Pakistan. Global electronics and telecom production is controlled by multinationals that have the necessary product and process technologies. Such enterprises are pivotal in spreading modern technology through explicit technology transfer as well as through technology spillovers and learning by doing. FDI through joint ventures should be particularly encouraged as collaboration with foreign manufacturers would help bring in new technology and shorten the learning curve for local producers, especially in the telecom sector.

Recent trends indicate that technology development takes place in proximity to production and marketing operations and that multinational subsidiaries and their joint venture partners are moving toward greater localization of technology development activities. In this scenario, special incentives for foreign investors that bring high technology to the electronics and telecom sectors is important. These could include tax holidays as well as the provision of physical infrastructure and amenities.

Global experience shows that innovation takes place in clusters where high-tech companies locate to take advantage of agglomeration and network economies (Acs \& Armington, 2006). Firms located in clusters develop positive feedback loops and synergy that support their research and innovation activities. The example of Silicon Valley amply illustrates how an entrepreneurial and innovative culture develops and thrives in a high-tech cluster.

While Pakistan has some industry clusters in different cities, their performance in terms of technology and innovation has not been up to the mark. There is need to promote industrial clusters of high-tech enterprises by providing amenities that would attract innovative enterprises. A key initiative would be to set up common facility centers in these clusters to facilitate the adoption of new technology and production of better quality 
goods. These centers should be equipped to provide advisory services, especially to small and medium enterprises.

Finally, a supportive regulatory and financial framework that enables dynamic enterprises to mediate risk, introduce new products, improve product quality and lower the cost of adopting modern technology would help raise technological capabilities. A key area that requires attention is the strengthening and strict enforcement of intellectual property rights and dispute settlement mechanisms. Strong intellectual property rights can be instrumental in encouraging domestic and foreign investment in high-tech enterprises. Similarly, there is considerable scope for promoting venture capital firms that can provide the necessary financing to promising technology-driven startups. Such entities could also support existing enterprises in new product development and innovations in production and process technologies.

\section{An Overview of the Telecommunications Sector in Pakistan}

Telecommunication and economic growth are strongly correlated: the modernization of various sectors of the economy is associated with a good telecommunication infrastructure. The telecom sector in Pakistan has shown sharp growth over the last decade. However, despite the significant progress it has made, the sector still lags behind comparable economies in terms of fixed-line density, mobile penetration and Internet usage. Thus, policies to develop this sector rely on the active role of the private sector. The role of the government should be confined to the provision of tax and other incentives and to creating an environment conducive to private sector activity. Some necessary steps for this purpose include formulating procedures for easy access to bandwidth, expanding broadband connectivity to enhance trade and employment opportunities and reducing the tax on telecommunications.

\subsection{Impact of Market Competition on Modernization in Telecom Technology}

With the advent of new technologies, telecom modernization in Pakistan has been concentrated in the core network (such as switches and concentrators). Technological upgrading in the wireline access network has remained slow due to the high cost involved. In analyzing the impact of telecom policies on the modernization and indigenization of this sector, we consider two policy instruments - market competition and investment - and 
their role in four subsectors: fixed local loop (FLL), wireless local loop (WLL), long-distance and international (LDI) and cellular.

\subsubsection{FLL Technology}

Pakistan's telecom deregulation policy coincided with the shift to modern technologies (wireless, Internet protocol, fiber optics) around the world. The fixed local line network did not attract enough investment, given the availability of alternatives and the heavy capital expenditure involved. Since there was no local content development, the demand for broadband and fixed-line technology remained minimal.

The driver of fixed-line growth in this scenario is broadband; the driver of broadband growth is local content. Since local content development and availability did not keep pace with the growth pattern of other markets, FLL growth also remained subdued. Furthermore, the weak law and order situation in Pakistan and the high cost of protecting this infrastructure has deterred investment in fixed network modernization.

Maintaining the FLL infrastructure is very costly. The right-of-way issues associated with this infrastructure are also a major constraint to the growth of FLL services. Furthermore, the disparity in taxes on import equipment for FLL services vis-à-vis others is substantial. With the implementation of the 3G network, the market for FLL services is expected to shrink further: it will be used for major content downloading while mobile services are used for lighter applications.

Although market competition was introduced by the deregulation policy, the fixed-line access network could not be modernized into a fiber network because it is largely copper-based. In the absence of any large players apart from PTCL, competition in this subsector is insignificant as other wireline local loop operators constitute only 1 percent of the total fixed network of subscribers.

\subsubsection{WLL Technology}

The market competition created by the telecom deregulation policy has led to the adoption of the latest technologies in the modern telecom network, with the aim of providing services at competitive rates. However, contrary to expectations, the effect of market competition on the growth of WLL services remains far below its potential. While more choice is available 
to customers and WLL rates are affordable, its use has not increased due to restrictions on handheld terminals and limited mobility.

\subsubsection{LDI Technology}

While greater competition has increased bandwidth, the voice traffic business of LDIs remains weak. The entry of Trans World Associates International into the market has led to lower international bandwidth prices. In the domestic sector, Wateen, Multinet and Linkdirect have built a national long-distance infrastructure, which has decreased national bandwidth prices. Furthermore, competition among LDIs has put further downward pressure on bandwidth rates. However, their voice traffic business remains weak as national LDI traffic from the mobile network is not open to LDIs and carrier selection/pre-selection facilities are not available to mobile networks, which constitute the majority of customers.

Whereas PTCL customers (only 3 percent of the total consumer base) can select an LDI operator, mobile customers (97 percent of total consumers) have no choice as such. On the other hand, the national long-distance traffic of mobile networks is not open to LDIs through equal access provisioning. This has had a twofold impact. First, it infringes on the rights of mobile customers due to discrimination. Second, it has caused loss of revenue from national long-distance services, which could have accrued to LDIs. Moreover, the number of LDI licenses issued (a total of 15) is excessive in relation to market requirements and size. The lack of an appropriate regulatory regime for new applications and services known as over-the-top content has also hampered the LDI sector in terms of business and technology.

\subsubsection{Cellular Networks}

The deregulation policy has strengthened competition in the cellular market. In order to remain commercially viable and earn a reasonable return on investment, competitors have introduced new technologies. As tariffs have declined, cellular operators have focused on reducing their capital and operating expenses to stay competitive. On the other hand, the new technology deployed has enabled cellular operators to improve their operational and organizational efficiency. As profit margins and average revenue per user have declined in this market, operators have opted for diversity and new revenue streams. Some cellular operators have their own LDIs, which have been critical in strengthening their business. 
With the recent introduction of 3G/4G networks, the future of the cellular telecom market in Pakistan rests with data. If competition is based on price alone, this will facilitate the consumer. However, it is equally important to balance this with investors' need to earn reasonable returns. In particular, there have been some incidents of predatory pricing, which is detrimental to new entrants and may restrict competition in the market. It is, therefore, essential to put in place an efficient regulatory mechanism to ensure healthy competition in the cellular market. This will be instrumental in boosting new investment in the latest technologies.

\subsection{Impact of Liberal Investment Regime on Modernization After Deregulation}

As no major investment group or foreign operator obtained a fixed license, the FLL sector did not have sufficient investment to modernize the network. The well-established PTCL was privatized and its new strategic owners did not bring in additional investment, instead recycling a portion of the revenues, thus slowing down the pace of modernization at the access level. On the other hand, a major factor inhibiting the growth of WLL is the restriction on handheld WLL terminals.

In this regard, it is pertinent to note that even wireline phones using cordless terminals have some sort of handheld facilities that have been denied to WLL customers. This has limited the opportunities for WLL growth. Limited mobility is a switch function and need not be implemented through restrictions on handheld sets. This restriction must be removed to help the WLL market and facilitate consumers. Other factors hindering WLL growth include the subsidy on fixed wireless terminals, limited mobility with associated quality-of-service problems and high import duties with an adverse effect on price setting. Thus, the cellular mobile sector, with no such limitations, has flourished to an optimum level, resulting in the rapid substitution of fixed-network services.

The WLL terminal market has been held back as local vendors consider it a risk to invest in less demanding CDMA-based WLL terminals. This has compelled service providers to supply terminals at subsidized rates to counter market pressure from the mobile networks and within the WLL sector. The provision of terminal equipment at subsidized rates has further burdened WLL operators and, consequently, affected the sector's investment potential. Another aspect is its shrinking margins. The market is highly price-sensitive and larger operators have an edge due to economies of scale and the synergy of service portfolios. Consequently, smaller 
operators find it hard to compete. Generally, WLL services are used by lowincome customers and, as a result, the total usage volume and consumption level are very low.

In terms of policy support, removing the 10 percent withholding tax would encourage an increase in the use of WLL services and help business operators enhance their scale of operation. Under the current regime, trading practices are not allowed, which contributes to the underutilization of scarce resources. If spectrum trading were allowed, operators lacking investment could sell the allocated spectrum to another interested operator, allowing them to exit the market.

\subsection{Impact of Market Competition and Liberal Investment Regime on the Indigenization of the Telecom Network}

Although the telecom market was limited and manufacturing volumes low before deregulation, there was significant local assembly and manufacture of network systems and equipment. After deregulation, the market expanded, requiring high volumes of telecom network equipment. Some passive elements of the telecom network, such as cables and connectors, have high rates of wear and tear so that there is continual demand for replacement parts.

The high demand for telecom equipment and supplies led to the establishment of companies providing such elements of the ICT network. These companies helped provide material for towers and parts of the network. In addition, the cabling of the optical fiber and batteries assembly gained momentum. Market competition boosted the cellular network and services alongside an improvement in electronics and software, which led to the availability of modern switches (NGN soft switches). The improved switches and high-end handsets enabled the development and launch of innovative services.

While market competition created opportunities for local manufacturing, local investors have generally failed to take full advantage of the market growth, given their lack of capital and expertise required to produce telecom equipment that meets world standards. The decline in domestic assembly operations has been exacerbated by an import policy under which taxes and duties on finished products are far lower than on CKD equipment. 
Before deregulation, investment was limited to passive network elements and the objective of indigenizing active or intelligent elements of the telecom network could not be achieved. After deregulation, market growth led to high and continual demand for telecom networks. The liberal investment regime created opportunities for local manufacturing, but the absence of local investors with sufficient capital and expertise meant that the sector could not produce telecom equipment to meet national as well as export requirements at competitive prices. Consequently, Pakistan relies heavily on imports of high-tech telecom network equipment.

Finally, the country lacks a clear policy on indigenization: whatever provisions are incorporated in various policies are not implemented in letter and spirit. There is a clear need to develop mechanisms for coping with the rapidly changing needs of the telecom industry, focusing in particular on the rationalization of tax and import tariffs and funding for R\&D.

\subsection{Taxation Issues in the Telecom Sector}

Tax policies play a significant role in market growth as well as the modernization and upgrading of the telecom sector. This makes it important to consider tax-related issues in Pakistan and the need to reform the tax policy pertaining to the sector. To begin with, the government levies a withholding tax on telecom services that is substantially higher than that charged on other segments of the economy. Most subscribers are nontax filers and cannot adjust their annual tax returns accordingly.

There are a total of 3.5 million national tax number holders in Pakistan, with an active taxpayer user base of around 0.8 million. Only 0.6 percent of mobile subscribers are actual taxpayers, which is staggeringly low. For the rest of the economy, withholding tax is usually charged at 10 percent, meaning that billions of rupees in advance income tax are not claimed. The Federal Board of Revenue should either abolish or rationalize this tax or devise a mechanism for charging only those subscribers who are otherwise taxable and liable to file a tax return.

General sales tax (GST) / federal excise duty (FED) is charged at 19.5 percent in Punjab, KP and Balochistan, 18 percent in Sindh and 18.5 percent in the rest of Pakistan. This is much higher than the average 16 percent GST charged on other sectors of the economy. This uneven treatment at a time when the telecom sector is one of the highest contributors to tax returns and has brought in significant FDI is bound to damage telecom operators and a 
fragile government. It is, therefore, imperative that the GST/FED on telecom services be reduced to the average GST rates in other sectors.

There are several tax proposals under consideration, but one such proposal is worth noting (Figure 3). Many in the telecom industry have, for years now, advocated a reduction in the indiscriminately high telecom taxes. It is also encouraging to have the State Bank of Pakistan discuss this issue at some length in its February 2016 report on the state of the economy, pointing out the "large untapped potential in the broadband segment" and urging the government to take measures to improve mobile and broadband use. The problems identified include "quality of services, complex price structure and high charges of devices" besides "heavy taxation" on devices, usage and SIM cards.

Figure 3: Impact of tax proposals on FBR revenue

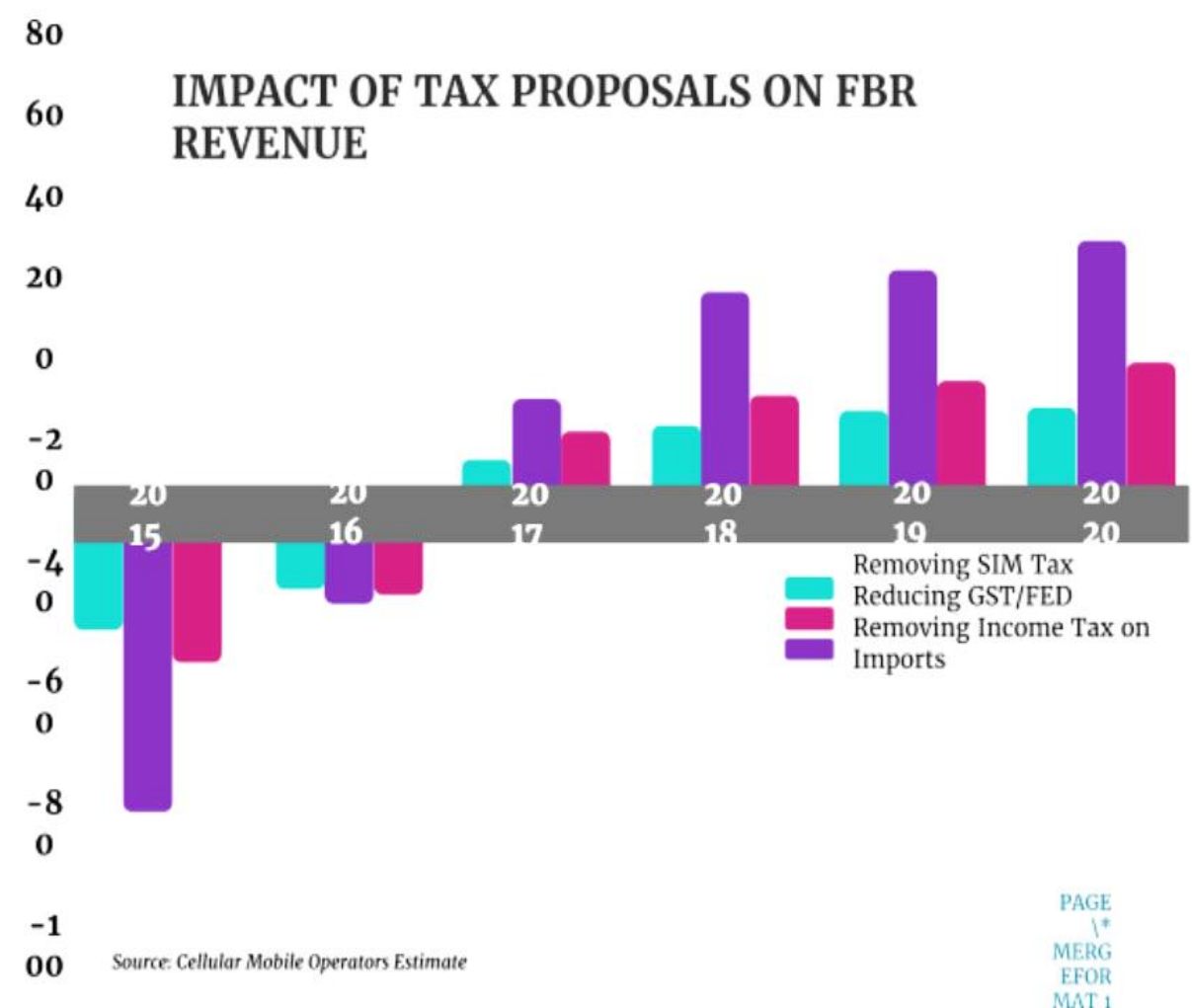

Source: Adapted from the Business Recorder, March 2016. 


\section{Concluding Remarks}

This paper has provided an economic and technological perspective on Pakistan's telecom sector, focusing in particular on the role of public policy in fostering innovation and economic growth. We argue that the telecom sector plays a critical role in the economy and public policy must be geared to promote its expansion while ensuring the sector is modernized and its technology upgraded. Such a policy framework must encompass measures to reward an entrepreneurial culture, promote human resource development, strengthen competition, provide incentives for technological upgrading and rationalize the tax and tariff structure.

Pakistan's discriminatory taxation structure has greatly hampered the growth of the telecom industry, indicating a need for tax reforms to ensure reasonable returns on investment in this sector. While the deregulation policy has encouraged telecom operators to modernize their technology to stay competitive, Pakistan remains heavily dependent on imported technology as the tariff structure has a built-in bias against the domestic assembly and manufacture of telecom equipment. It is thus important to rationalize the tariff structure and create a level playing field for domestic telecom producers and assemblers. A policy environment conducive to the growth of the telecom sector is expected to yield significant dividends in terms of an improvement in productivity, innovation and the modernization of technology, leading to robust economic growth. 


\section{References}

Acemoglu, D., Johnson, S., \& Robinson, J. (2005). Institutions as the fundamental cause of long-run growth. In P. Aghion \& S. Durlauf (Eds.), Handbook of economic growth (vol. 1A). Amsterdam: NorthHolland.

Acs, Z. (2006). How is entrepreneurship good for economic growth? Innovations: Technology, Governance and Globalization, 1(1), 97-107.

Acs, Z. J., \& Armington, C. (2006). Entrepreneurship, geography and American economic growth. Cambridge: Cambridge University Press.

Acs, Z. J., \& Audretsch, D. B. (1989). Patents as a measure of innovative activity. Kyklos, 42(2), 171-180.

Acs, Z. J., \& Szerb, L. (2007). Entrepreneurship, economic growth and public policy. Small Business Economics, 28(2/3), 109-122.

Audretsch, D. B., Keilbach, M. C., \& Lehmann, E. (2006). Entrepreneurship and economic growth. Oxford: Oxford University Press.

Barro, R. J. (1990). Government spending in a simple model of endogenous growth. Journal of Political Economy, 98(5), S103-S125.

Dollar, D., \& Kraay, A. (2003). Institutions, trade and growth. Journal of Monetary Economics, 50(1), 133-162.

Easterly, W., \& Levine, R. (2001). What have we learned from a decade of empirical research on growth? It's not factor accumulation: Stylized facts and growth models. World Bank Economic Review, 15(2), 177219.

El-Erian, M. (2015, October 21). Governments must self-disrupt to innovate. The World Post. Retrieved from http://www.huffingtonpost.com/mohamed-aelerian/government-self-disrupt-innovation_b_8344218.html

Fan, P. (2011). Innovation capacity and economic development: China and India. Economic Change and Restructuring, 44(1/2), 49-73.

Grossman, G. M., \& Helpman, E. (1990). Trade, innovation and growth. American Economic Review, 80(2), 86-91. 
Grossman, G. M., \& Helpman, E. (1994). Endogenous innovation in the theory of growth. Journal of Economic Perspectives, 8(1), 23-44.

Hassan, D. (2014). Knowledge management practices in Pakistan's telecom services sector. Lahore Journal of Business, 3(1), 55-74.

King, R. G., \& Rebelo, S. (1990). Public policy and economic growth: Developing neoclassical implications (Working Paper No. 3338). Cambridge, MA: National Bureau of Economic Research.

Lucas, R. E. (1988). On the mechanics of economic development. Journal of Monetary Economics, 22(1), 3-42.

Mangla, I. U., \& Din, M. (2015). The impact of the macroeconomic environment on Pakistan's manufacturing sector [Special edition]. Lahore Journal of Economics, 20, 241-260.

Rahman, A., Kemal, A. R., Siddiqui, R., ... Khan, S. H. (2005). Technologybased industrial vision and strategy for Pakistan's socioeconomic development. Islamabad: Pakistan Institute of Development Economics.

Romer, P. M. (1986). Increasing returns and long-run growth. Journal of Political Economy, 94(5), 1002-1037.

Romer, P. M. (1994). The origins of endogenous growth. Journal of Economic Perspectives, 8(1), 3-22.

Schumpeter, J. A. (1942). Capitalism, socialism and democracy. New York: Harper \& Row.

Solow, R. M. (1956). A contribution to the theory of economic growth. Quarterly Journal of Economics, 70(1), 65-94.

Swan, T. W. (1956). Economic growth and capital accumulation. Economic Record, 32(2), 334-361. 